\title{
POST-PRINT
}

Submitted, accepted and published in

International Journal of Hydrogen Energy 38, 15084-15091 (2013); DOI:

10.1016/j.ijhydene.2013.09.086

\section{Catalytic decomposition of biogas to produce hydrogen rich fuels for SI engines and valuable nanocarbons}

S. de Llobet ${ }^{\text {a }}$, J.L. Pinilla ${ }^{\text {a }}$, R. Moliner ${ }^{\text {a }}$, I. Suelves ${ }^{\text {a, }}$, J. Arroyo ${ }^{\text {b }}$, F. Moreno ${ }^{\text {b }}$, M. Muñoz $^{\text {b }}$, C. Monné ${ }^{\text {b }}$ I. Cameán ${ }^{c}$, A. Ramos ${ }^{c}$, N. Cuesta ${ }^{c}$, A.B. Garcia ${ }^{c}$

${ }^{a}$ Instituto de Carboquímica. CSIC. C/ Miguel Luesma 4. 50018 Zaragoza, Spain

${ }^{b}$ Dpto. de Ingeniería Mecánica. Laboratorio de Motores. Universidad de Zaragoza. (edif. B). C/ María de Luna s/n. 50018 Zaragoza. Spain

${ }^{c}$ Instituto Nacional del Carbón. CSIC. C/ Francisco Pintado Fé 26. 33011 Oviedo. Spain

\section{Abstract}

Catalytic Decomposition of Biogas (CDB), producing simultaneously syngases (SG), with high hydrogen contents, for spark ignition (SI) engines and bio-carbon nanofibers (BCNFs) to be further used as precursor of synthetic graphite, is presented as an alternative to the usual direct combustion. Synthetic biogas mixtures were decomposed in the presence of a Ni catalyst at different temperatures and the SG thus produced were further tested as fuel in a specifically designed SI engine, whereas the BCNFs were subjected to heat treatment to graphitize. The influence of CDB process conditions on product yields and properties, the effect of SG composition/quality in SI engine performance and emissions, as compared with the use of raw biogas and the influence

\footnotetext{
* Corresponding author: fax: +34 97673 3318, e-mail address: isuelves@icb.csic.es (I. Suelves)
} 
of BCNFs characteristics on the structural and textural properties of the graphitic materials have been studied. The syngases presented better combustion characteristics than biogas resulting in higher engine brake thermal efficiencies and lower exhaust emissions. Furthermore, high added value graphite-like materials, with a crystalline structure similar to that of oil-derived graphite which is currently commercialized to be used as anode in rechargeable lithium-ion batteries, were prepared. 


\section{INTRODUCTION}

Biogas is an energy source composed mainly of $\mathrm{CH}_{4}$ and $\mathrm{CO}_{2}$ from which electricity and heat are produced by its direct combustion in co-generation plants [1]. Nevertheless, the exploitation of the biogas for different applications like the production of hydrogen [2], syngas [3], high added value carbon materials [4] or bio-methane [5] appear as an interesting option, particularly when considering the renewable origin of the source. In this context, the Catalytic Decomposition of Biogas (CDB) to simultaneously produce syngases (SG) with high hydrogen contents and bio-carbon nanofibers (BCNFs) is a potential alternative to be considered. By this process, high quality syngas composed by $\mathrm{CO}$ and $\mathrm{H}_{2}$ (with smaller amounts of unconverted $\mathrm{CH}_{4}$ and $\mathrm{CO}_{2}$ ) was obtained from the original biogas [6]. However, as compared to the direct biogas combustion, CDB is energetically penalized since it is an endothermic process. Therefore, the economical feasibility of the CDB process would be highly determined by the final utilization of both BCNFs and SG.

Since the 1940's, synthetic gases have been used as fuel in Internal Combustion Engines (ICE) [7]. It is estimated that during this period, around one million vehicles used gas derived from biomass as fuel. From that time on, it has been opened a wide field of research in power generation by dual fuel spark ignition (SI) and diesel engines. The use of synthetic gases combined with traditional fuels implies a stable combustion, even when the $80 \%$ of the traditional fuel is replaced by gaseous fuel [7-11]. Furthermore, it has been demonstrated that the use of synthetic gases decrease $\mathrm{HC}, \mathrm{CO}$ and NOx emissions in spark ignition (SI) engines compared with gasoline [12-16]. Several works have been focused in study the benefits in performance and emissions of synthetic gases depending on fuel composition [17]. It has been found that presence of 
hydrogen in gaseous fuels allows achieving efficiencies similar to natural gas [18]. Moreover, the lean operation limit can be extended as the hydrogen fraction increases, which implies benefits in emissions over natural gas $[17,18]$. Due to these features, synthetic gases have become a potential alternative source of energy which gives good results as fuel in ICE.

Carbon nanofibers (CNFs) from the catalytic decomposition of methane have been successfully applied by our research group as catalyst support in proton exchange membrane (PEM) fuel cells [19], additive in epoxy-based composites [20] and precursors of synthetic graphite [21, 22]. Among these potential uses, the graphitization of CNFs is a very interesting approach since synthetic graphite is highly valuable carbon material with a wide range of applications, including energy storage devices, such as anode materials in lithium-ion batteries (LIB). In this respect, materials with crystalline parameters in the range of synthetic graphite which are currently employed in energy applications were prepared from above mentioned methane-based CNFs at temperatures above $2400{ }^{\circ} \mathrm{C}$, mainly because of the catalytic effect of the metalcontaining species [22]. These materials were further tested as anodes in LIB showing good performance in terms of reversible capacity, cyclability and cycling efficiency [23].

The purpose of this work is to study the implementation of the CDB process for the valorization of biogas as an alternative to the usual direct combustion through the simultaneous production of hydrogen-rich fuels for SI engines and BCNFs to be further used as precursor of synthetic graphite. To this end, synthetic biogas mixtures were decomposed in the presence of a $\mathrm{Ni}$ catalyst in a rotary-bed reactor under different experimental conditions and the SG thus produced were further tested as fuel in a specifically designed SI engine, whereas BCNFs were heat treated in the temperature 
interval 2600-2800 ${ }^{\circ} \mathrm{C}$. Emphasis was placed on three aspects: (i) the influence of $\mathrm{CH}_{4}: \mathrm{CO}_{2}$ ratio and $\mathrm{CDB}$ process temperature on $\mathrm{SG}$ composition/quality and on BCNFs structure, (ii) the effect of SG composition/quality in SI engine performance and emissions as compared with the use of raw biogas and (iii) the influence of BCNFs characteristics on the structural and textural properties of the graphitic materials prepared.

\section{EXPERIMENTAL}

\subsection{Catalytic decomposition of biogas: procedure and products}

Biogas is composed mainly of $\mathrm{CH}_{4}$ and $\mathrm{CO}_{2}$, but it could also contain traces of other gases such as $\mathrm{N}_{2}, \mathrm{H}_{2}, \mathrm{O}_{2}, \mathrm{H}_{2} \mathrm{~S}, \mathrm{NH}_{3}$ or siloxanes. Particularly, $\mathrm{H}_{2} \mathrm{~S}$ cause severe metal catalysts deactivation and desulphurization of the biogas would be necessary [5]. However, removal of harmful impurities that cause corrosion problems (sulphur compounds) or damages in the engine (siloxanes) is also necessary if biogas is used as fuel $[24,25]$. For that reason, three synthetic biogas mixtures containing only $\mathrm{CH}_{4}$ and $\mathrm{CO}_{2}$ with volume ratios (v:v) of 50:50, 60:40 and 70:30 designed as BG1, BG2 and BG3, were selected. The catalytic decomposition of these biogases to produce SG and BCNFs was carried out in a rotary-bed reactor heated by an electric furnace. Additional information of the experimental apparatus could be found in [26]. A cold trap was placed after the reactor to condense the steam formed during the reaction. In a typical test, $5 \mathrm{~g}$ of fresh catalyst denoted as $\mathrm{Ni} / \mathrm{Al}_{2} \mathrm{O}_{3}(\mathrm{Ni}: \mathrm{Al}$ molar ratio of 2:1) and prepared by the fusion method [27], were loaded in the reactor. This catalyst was extensively used in catalytic decomposition of methane and $\mathrm{CH}_{4}: \mathrm{CO}_{2}$ mixtures and a thorough characterization can be found in previous work of our research group [28, 29]. A total 
flow rate of $6 \mathrm{~L}_{\mathrm{N}} \cdot \mathrm{h}^{-1}$ was chosen to obtain a WHSV (Weight Hourly Space Velocity, defined here as the total flow rate at normal conditions per gram of catalyst initially loaded) of $30 \mathrm{~L}_{\mathrm{N}} \cdot \mathrm{g}_{\mathrm{cat}}{ }^{-1} \cdot \mathrm{h}^{-1}$. Experiments were carried out at two different temperatures, 600 and $700{ }^{\circ} \mathrm{C}$. Prior to each test, catalyst was reduced with a $\mathrm{H}_{2}$ stream at $550{ }^{\circ} \mathrm{C}$ for 1h. A deviation less of the $5 \%$ for $\mathrm{C}, \mathrm{O}$ and $\mathrm{H}$ was obtained in the mass balances.

Following the raw biogas designation, the syngases and the bio-carbon nanofibers produced were named as SG1, SG2 and SG3, and BCNF1, BCNF2 and BCNF3, respectively. Moreover, the number 6 for $600{ }^{\circ} \mathrm{C}$ or 7 for $700{ }^{\circ} \mathrm{C}$ was added to discern the CDB reaction temperature, such as SG1-6 and BCNF1-6 for those produced with a $\mathrm{CH}_{4}: \mathrm{CO}_{2}$ volume ratio of $50: 50$ and at $600{ }^{\circ} \mathrm{C}$. The composition of the SG was determined by gas chromatography in a micro GC Varian CP4900 equipped with two packed columns (Molecular Sieve and Porapack) and a TCD detector to quantify $\mathrm{H}_{2}$, $\mathrm{CO}, \mathrm{CH}_{4}$ and $\mathrm{CO}_{2}$ concentrations. The $\mathrm{Ni}$ and $\mathrm{Al}$ contents in the BCNFs, as determined by inductively coupled plasma-optical emission spectroscopy, are reported in Table $\mathbf{1}$. BCNFs with different $\mathrm{Si} / \mathrm{Ni}$ atomic ratio $(1,5$ and 7$)$ were prepared by mixing the asproduced BCNFs containing $\mathrm{Ni}$ from the catalysts with powder silica and they were named by adding this atomic ratio, such as BCNF1-6-1.

\subsection{SI engine tests of biogas-based SG}

The engine tests were conducted in a SI engine intended for use in vehicles. The original engine (see specifications in Table 2) was adapted for dual fuel operation (gasoline and gaseous fuels). A scheme of the engine test bench is shown in Figure 1.

As it can be seen, the engine was coupled to a dynamometer in order to work at different conditions of speed and load. A complete explanation about the apparatus used to measure the variables acquired in these tests can be found in [30]. 
Pollutant emissions were measured using an installation based in a group of Signal Instruments exhaust gas analysers, deeply described in [31].

In order to remove uncertainty associated with the ICE, the tests conditions of power, fuel consumption and pollutant emissions were performed strictly following the current European directives related to engine testing.

SG simulating those produced in the catalytic decomposition of a $\mathrm{CH}_{4}: \mathrm{CO}_{2}$ mixture of 50:50 (v:v) at $600{ }^{\circ} \mathrm{C}$ (SG1-6) and $700{ }^{\circ} \mathrm{C}$ (SG1-7) (see Table 3) were supplied by Linde Industrial Gases and named by adding an *, such as SG1-6* and SG1-7*. These simulated SG, whose composition is the same as SG1-6 and SG1-7 reported in Table 3, were used as fuels to study the performance and emissions of the SI engine, which specifications appear in Table 2. For comparison, a synthetic biogas (BG2) was also tested.

For each fuel gas, ignition map was not changed and the engine was tested according to the maximum and minimum brake thermal efficiency (BTE) values at full load (wide open throttle) for different rotation speeds (from $2000 \mathrm{rpm}$ to $4500 \mathrm{rpm}$ ) under three equivalence ratios $(\Phi$, ratio of the actual fuel/air relation to the stoichiometric), namely $\Phi=1, \Phi=0.85$ and $\Phi=0.7$. Calculation of BTE was realized according to the first law of thermodynamics and it is defined by equation (1):

$$
\mathrm{BTE}=\frac{\mathrm{P}_{\mathrm{b}}}{\dot{\mathrm{m}}_{\mathrm{f}} \times \mathrm{LHV}}
$$

Where $P_{b}(\mathrm{~kW})$ is the brake power measured by the dynamometer coupled to the engine, $\quad(\mathrm{kg} / \mathrm{s})$ the mass flow of fuel consumed by the engine and $L H V(\mathrm{~kJ} / \mathrm{kg})$ the Lower Heating Value of the fuel. The use of equivalence ratios less than one (air excess) with gaseous fuels can result in an increment in thermal efficiency and a reduction in pollutant emissions [32]. The presence of hydrogen in the SG allowed the use of lean conditions with good results. However, it was impossible to reach the $\Phi=0.7$ 
with the synthetic biogas due to the engine instability produced by this gas at these conditions [33].

\subsection{Heat treatment of BCNFs}

The BCNFs were heat treated in the temperature interval of $2600-2800{ }^{\circ} \mathrm{C}$ for $1 \mathrm{~h}$ in an argon flow using a graphite furnace. The heating rates were $25^{\circ} \mathrm{C} \cdot \mathrm{min}^{-1}$ from room temperature to $1000{ }^{\circ} \mathrm{C}, 20{ }^{\circ} \mathrm{C} \cdot \mathrm{min}^{-1}$ in the range $1000-2000{ }^{\circ} \mathrm{C}$ and $10{ }^{\circ} \mathrm{C} \cdot \mathrm{min}^{-1}$ from $2000{ }^{\circ} \mathrm{C}$ to the prescribed temperature. The graphitic materials thus prepared were named by adding a suffix with the treatment temperature in the BCNFs designation, such as BCNF1-6/2600 or BCNF1-6-7/2600. Therefore, BCNF1-6-7/2600 stands for a bio-carbon nanofiber obtained from the catalytic decomposition of the BG1 at $600{ }^{\circ} \mathrm{C}$, with a Si/Ni atomic ratio of 7 and heat treated at $2600{ }^{\circ} \mathrm{C}$.

\subsection{Structural characterization techniques: XRD, SEM and TEM}

The diffractograms were recorded in a Bruker D8 powder diffractometer equipped with a Göbel mirror in the incident beam and a parallel-slits analyzer in the diffracted beam. Diffraction data were collected by step scanning with a step size of $0.02^{\circ} 2 \theta$ and scan step of $3 \mathrm{~s}$. For each sample, three diffractograms were obtained, using a representative batch of sample for each run. The interlayer spacing, $\mathrm{d}_{002}$, was determined from the position of the (002) peak by applying Bragg's equation. The crystallite sizes, $\mathrm{L}_{c}$ and $\mathrm{L}_{\mathrm{a}}$, were calculated from (002) and (110) peaks, respectively, using the Scherrer formula, with values of $K=0.9$ for $L_{c}$ and $K=1.84$ for $L_{a}$ [34]. The broadening of diffraction peaks due to instrumental factors was corrected with the use of silicon standard. Typical standard errors of the XRD parameters are $<3 \%$ and $<5 \%$ of the reported values for $\mathrm{L}_{\mathrm{c}}$ and $\mathrm{L}_{\mathrm{a}}$, respectively; the interlayer spacing values are more precise, with standard 
errors of $<0.06 \%$. These parameters are used to evaluate the degree of structural order of the materials [35].

The morphology of the materials was studied with a scanning electron microscope (SEM) (Hitachi S-3400) coupled to a Si/Li detector for energy dispersive X-ray (EDX) analysis. Transmission Electron Microscopy (TEM) was carried out on a JEOL-2000 FXII microscope operating at $200 \mathrm{kV}$. Firstly, samples were dispersed in ethanol and a drop of solution was deposited on a classical TEM copper grid, previously covered by a holey amorphous carbon film. Examination of the sample was focused on parts of the samples lying across the holes to obtain information free of the contribution of the amorphous supporting carbon film.

\section{RESULTS AND DISCUSSION}

\subsection{SG and $\mathrm{BCNFs}$ characteristics: influence of $\mathrm{CH}_{4}: \mathrm{CO}_{2}$ volume ratio and $\mathrm{CDB}$ process temperature}

The compositions of the SG and the BCNFs production $\left(\mathrm{gC} \cdot \mathrm{g}_{\mathrm{cat}}{ }^{-1} \cdot \mathrm{h}^{-1}\right.$, grams of carbon per gram of catalyst initially loaded and per hour) obtained in the catalytic decomposition of three synthetic biogases with $\mathrm{CH}_{4}: \mathrm{CO}_{2}$ volume ratios of 50:50, 60:40 and 70:30, typically present in natural biogas, along with $\mathrm{CH}_{4}$ and $\mathrm{CO}_{2}$ conversions and the molar expansion factor $\left(\varepsilon_{\mathrm{a}}\right)$ are reported in Table 3. The CDB experiments were performed at $600{ }^{\circ} \mathrm{C}$ and $700{ }^{\circ} \mathrm{C}$ since according to thermodynamic calculations [6], carbon formation is favoured in this temperature interval. Besides this, $\mathrm{CH}_{4}$ and $\mathrm{CO}_{2}$ conversions experimentally obtained at these temperatures allow to obtain different SG compositions to study afterwards their effect on the engine performance. 
As expected due to the endothermic nature of the $\mathrm{CDB}$ process $\left(\mathrm{CH}_{4}+\mathrm{CO}_{2} \leftrightarrow 2 \mathrm{H}_{2}+\right.$ $\left.2 \mathrm{CO}, \Delta \mathrm{H}^{\circ}=247 \mathrm{~kJ} \cdot \mathrm{mol}^{-1}\right), \mathrm{CH}_{4}$ and $\mathrm{CO}_{2}$ conversions were higher at $700{ }^{\circ} \mathrm{C}$ than at 600 ${ }^{\circ} \mathrm{C}$ [28]. $\mathrm{H}_{2}$ and $\mathrm{CO}$ concentrations in $\mathrm{SG}$ increased upon process temperature. As a result, $\mathrm{H}_{2}$ concentrations in the syngas up to 53\% (SG3-7) were achieved by decomposing $\mathrm{BG} 3$ at $700{ }^{\circ} \mathrm{C}$. Moreover, the biogas $\mathrm{CH}_{4}: \mathrm{CO}_{2}$ volume ratio also influences SG composition. Thus, $\mathrm{H}_{2}: \mathrm{CO}$ volume ratios of ca. 1 and 1.8 were determined in the syngases produced from BG1 and BG3 at $700{ }^{\circ} \mathrm{C}$, respectively. With regard to $\mathrm{CO}_{2}$ concentration, it was observed to decrease by rising biogas $\mathrm{CH}_{4}: \mathrm{CO}_{2}$ volume ratio and/or temperature. The concentration of $\mathrm{CO}_{2}$ in the syngas has to be taken into account because it is an inert gas and therefore, an important factor affecting the further engine performance [17, 18]. Finally, it is worth to mention that as a consequence of the molar expansion occurring in the $\mathrm{CDB}$, an increase of the gas volume leaving the reactor is observed. This increase is larger at 700 than at $600{ }^{\circ} \mathrm{C}$ due to the endothermicity of the process and can reach values higher than $61 \%$.

The amount of carbon material obtained as co-product in the CDB process depends on the operating conditions (temperature and $\mathrm{CH}_{4}: \mathrm{CO}_{2}$ volume ratio) and it ranged between 1.4 and $3.6 \mathrm{gC} \cdot \mathrm{gcat}^{-1} \cdot \mathrm{h}^{-1}$ (Table 3). This material was deposited as filamentous nanocarbons few microns long (BNCF) as seen in Figure 2 in which some representative SEM and TEM micrographs, specifically those of BCNF1-6 and BCNF17, are shown. By comparing the images of these BCNFs, differences with regard to aspect and microstructure are evident. Thus, BCNF1-7 (Figure 2.b) are narrower, more tangled and more compacted than BCNF1-6 (Figure 2.a). In addition, the former shows a mixture of fishbone and ribbon microstructure formed of parallel graphene layers, which are, respectively tilted or parallel with respect to the fiber axis bearing the $\mathrm{Ni}$ particle at the tip and showing an inner hollow of up to $10 \mathrm{~nm}$ width (Figure 2.d), 
whereas only solid (no apparent hollow core) fishbone microstructure with well-defined shaped Ni particles at the tip was found in the BCNF1-6 (Figure 2.c). Apparently, the increase of the process temperature from $600{ }^{\circ} \mathrm{C}$ to $700{ }^{\circ} \mathrm{C}$, promotes the formation of ribbon microstructures in these BCNFs. The morphology of the other BCNFs produced in this work were similar, therefore their images are not given.

\subsection{Performance and emissions of the SI engine}

\subsubsection{Brake thermal efficiency}

The engine performance has been evaluated according to the maximum and minimum BTE values obtained at full load and under the above three equivalence ratios (Table 4). As it can be seen, the maximum BTE of the engine fuelled with biogas (BG2) was achieved at $\Phi=1$. However, with the syngases (SG1-6*, SG1-7*) higher efficiencies were obtained at $\Phi=0.85$ because of the extension of the lean operation limit provoked by the presence of $\mathrm{H}_{2}$ in their compositions. Overall, better engine efficiencies were determined by using the syngases. Thus, maximum engine brake thermal efficiencies of $31.65 \%$ and $30.48 \%$ were obtained for SG1-6* and SG1-7*, respectively, against a value of $27.24 \%$ for the biogas. Only at $\Phi=1$ and high engine speeds ( $4500 \mathrm{rpm}$ ), the use of SG1-7* as fuel led to a drop in BTE, due to the elevated concentration of $\mathrm{H}_{2}$ in this syngas (Table 3). The low energy density of hydrogen provoked an increase in the fuel consumption and consequently in the $\mathrm{CO}_{2}$ flow, decreasing the power generated.

\subsubsection{Exhaust Emissions}

Figure 3 shows the brake specific (BS) exhaust emissions $\left(\mathrm{CO}_{2}, \mathrm{CO}, \mathrm{HC}, \mathrm{NO}_{\mathrm{x}}\right)$ of the engine in the points of maximum BTE for the two syngases (SG1-6* and SG1-7*) and the biogas (BG2). As compared with biogas, the use of the syngases as fuel led to lower 
$\mathrm{BSCO}_{2}, \mathrm{BSCO}$ and $\mathrm{BSHC}$ concentrations in the exhaust gases (Figure 3a-c). The smaller $\mathrm{CO}_{2}$ contents in SG1-6* and SG1-7* with respect to $\mathrm{BG} 2$, can account for the decrease of $\mathrm{CO}_{2}$ emissions. Furthermore, it should be considered that the stoichiometric conditions $(\Phi=1)$ under which we obtained the maximum BTE with biogas together with a power fall as a consequence of $\mathrm{CO}_{2}$ dilution also contributed to increase $\mathrm{BSCO}_{2}$ emissions.

Despite the fact that BSCO emissions at lean conditions should be minimum, the presence of $\mathrm{CO}$ in the syngas favours its appearance in the exhaust gases, since part of this CO remains unburned. Even so, a significant fall of the BSCO emissions was observed by using SG1-6* and SG1-7* (Figure 3b). CO emissions depends mainly on the equivalence ratio for the maximum BTE that, as mentioned in Section 3.2.1, was higher for the biogas $(\Phi=1)$ than for the syngases $(\Phi=0.85)$, thus explaining the decrease of these emissions when the later were used as engine fuel [32].

The main proportion of hydrocarbons in the exhaust gases from either biogas or syngases come from the unburned part of $\mathrm{CH}_{4}$. Therefore, as seen in Figure 3c, the BSHC emissions followed the sequence BG2 > SG1-6* > SG1-7*, which match with the concentration of $\mathrm{CH}_{4}$ in these fuels, $60 \%>26 \%>11 \%$.

Unlike $\mathrm{BSCO}_{2}, \mathrm{BSCO}$ and $\mathrm{BSHC}, \mathrm{BSNO}_{\mathrm{x}}$ emissions from the engine were higher by using the syngases as fuels, specifically in the case of SG1-7* (Figure 3d). This result is associated with the presence of hydrogen in the syngases. Hydrogen increases the incylinder temperature which has a strong influence in the $\mathrm{NO}_{\mathrm{x}}$ generation. Thus, $\mathrm{BSNO}_{\mathrm{x}}$ emissions of $32.10 \mathrm{~g} \cdot \mathrm{kWh}^{-1}, 4.90 \mathrm{~g} \cdot \mathrm{kWh}^{-1}$ and $1.51 \mathrm{~g} \cdot \mathrm{kWh}^{-1}$ were measured from SG17*, SG1-6* and BG2, respectively. This implies that the use of syngases as fuels in the engine will require an additional $\mathrm{NO}_{\mathrm{x}}$ reduction step, like exhaust gas recirculation 
(EGR) or water injection, in order to maintain these emissions within an acceptable range, specifically as the hydrogen concentration in the syngas increases.

\subsection{Structural properties of the heat-treated BCNFs}

To complete the study of the revaluation of biogas as an alternative to the usual direct combustion, the graphitization of the BCNFs produced in the $\mathrm{CDB}$ when feeding a $\mathrm{CH}_{4}: \mathrm{CO}_{2}$ mixture with a 50:50 volume ratio (BG1) was investigated. The XRD parameters of the materials prepared as well as those of the BCNF1-6 and BCNF1-7 bio-nanofibers used as precursors are collected in Table 5. As indicated by the values of the interlayer spacing, $\mathrm{d}_{002}$, and the mean crystallites sizes, $\mathrm{L}_{\mathrm{a}}$ and $\mathrm{L}_{\mathfrak{c}}$, these as-prepared BCNFs already have a certain degree of structural order and therefore, they are classified within graphitic carbons [36]. The heat treatment of the BCNFs at 2600-2800 ${ }^{\circ} \mathrm{C}$ leads to more crystalline materials as shown by the decrease of $\mathrm{d}_{002}$, and the growth of the crystallites, particularly along the basal plane $\left(\mathrm{L}_{\mathrm{a}}\right)$ what can be attributed to the preferential coalescence of adjacent crystallites in this direction, or to the coexistence of this lateral coalescence with a vegetative process (growth in-plane by incorporation of disordered carbon) what has been reported to explain the crystal growth in carbons during heat treatment [37]. Unlike $\mathrm{L}_{\mathrm{a}}$, the growth of $\mathrm{L}_{\mathrm{c}}$ just occurs by coalescence along the c-axis. As a result, graphitic materials with interlayer spacing in the range of 0.3400 $\mathrm{nm}$ and crystallites sizes $\mathrm{L}_{\mathrm{a}}$ up to $\sim 40 \mathrm{~nm}$ and $\mathrm{L}_{\mathrm{c}}$ of $\sim 9 \mathrm{~nm}$ are obtained from BCNF1-6 and BCNF1-7 (Table 5). Furthermore, more structurally ordered materials have been attained by heating at $2800^{\circ} \mathrm{C}$ the as-prepared $\mathrm{BCNFs}$ containing added silica. As a matter of fact, the degree of structural order of the materials progressively improves on increasing $\mathrm{Si} / \mathrm{Ni}$ atomic ratio in the BCNFs (BCNF1-6-1,5,7 or BCNF1-7-1,5,7). To give such an example, BCNF1-7-1/2800, BCNF1-7-5/2800 and BCNF1-7-7/2800 
materials show $\mathrm{d}_{002}$ values of $0.3390 \mathrm{~nm}, 0.3362 \mathrm{~nm}$ and $0.3361 \mathrm{~nm}$, whereas the corresponding crystallites size, $\mathrm{L}_{\mathrm{c}}$, are $\sim 12 \mathrm{~nm}, \sim 36 \mathrm{~nm}$ and $\sim 42 \mathrm{~nm}$. The silicon present in the BCNFs $[38,39]$ could react with the disordered carbons in the edges planes of the crystallites [38, 39] to form carbides which subsequent decomposition would lead to the formation of graphitic carbon. Therefore, the size of the graphene layers would be increased. As a consequence of this in-plane crystallite growth, the coalescence of the crystallites along the a-axis could also be favoured, thus explaining the large $\mathrm{L}_{\mathrm{a}}$ sizes (up to $99 \mathrm{~nm}$ ) of the graphitic materials prepared from these BCNFs containing Si (Table 5).

A comparative analysis of the graphitization results of the two BCNFs studied, shown in Table 5, allows concluding that materials with higher degree of graphitic structural order were obtained from BCNF1-7. Although to the best of our knowledge, the work present in this paper is the first one showing the graphitization of biogas-based carbon nanofibers, the graphitization of fossil fuel-based carbon nanofibers (CNFs) with various microstructures, including the above mentioned ribbon and fishbone types present in the BCNFs, has been studied in detail [40]. In terms of structure, an overall improvement of the graphitic three-dimensional order was also reported to occur. The extent of this improvement was found to be very variable depending of the CNFs and no apparent trends as regards microstructure or other characteristics was observed. However, provided that the composition (Table 1) and the structural parameters of BCNF1-6 and BCNF1-7 are similar (Table 5) the significant difference in the degree of graphitizability can only be clarified attending to their different microstructure (Figure 2). Therefore, it seems that the ribbon microstructure which is only present in BCNF1-7 facilitates somewhat the alignment of the graphene layers and the coalescence of the crystallites. Additional work should be done to confirm this point. 
Finally, it was found interesting to compare the structural parameters of the graphitic materials that were prepared in this work from the BCNFs, already discussed, with those measured for commercial oil-derived synthetic graphites (petroleum coke being the main precursor) which are currently commercialized to be used as anode in lithiumion batteries. Two graphites, G1 and G2, were selected and they were characterized following identical routines to those described therein. XRD results are also collected in Table 5. As seen, the heat treatment of BCNF1-7 at $2800{ }^{\circ} \mathrm{C}$ results in graphitic materials that have a three-dimensional structure comparable to that of G1 and G2 graphites. Thus, $\mathrm{d}_{002}$ of $0.3361 \mathrm{~nm}$ and $\mathrm{L}_{\mathrm{c}}$ and $\mathrm{L}_{\mathrm{a}}$ up to $\sim 42 \mathrm{~nm}$ and $\sim 99 \mathrm{~nm}$ were measured for BCNF1-7-7/2800 material.

\section{Conclusions}

The Catalytic Decomposition of Biogas was carried out using a $\mathrm{Ni} / \mathrm{Al}_{2} \mathrm{O}_{3}$ catalyst, employing typical $\mathrm{CH}_{4}: \mathrm{CO}_{2}$ biogas volume ratios of 50:50, 60:40 and 70:30 at two temperatures, 600 and $700{ }^{\circ} \mathrm{C}$, producing simultaneously bio-carbon nanofibers (BCNFs) and syngas (SG) with different characteristics as regards microstructure and composition, respectively. Apparently, the increase of the process temperature promotes the formation of ribbon microstructures in the BCNFs as well as the proportion of hydrogen in the $\mathrm{SG}$. The syngases obtained in the $\mathrm{CDB}$, with a $\mathrm{CH}_{4}: \mathrm{CO}_{2}$ volume ratio of 50:50 at 600 and $700{ }^{\circ} \mathrm{C}$, were satisfactorily used as fuel in an automotive SI engine, previously adapted to work in dual mode. Maximum engine brake thermal efficiencies (BTE) up to $~ 32 \%$ were achieved with both SG, these values being higher than that of the raw biogas $(27.24 \%)$. Furthermore, with the exception of $\mathrm{NO}_{\mathrm{x}}$, the exhaust emissions $\left(\mathrm{CO}_{2}, \mathrm{CO}\right.$ and $\left.\mathrm{HC}\right)$ were significantly reduced by using $\mathrm{SG}$ as fuel. Additionally, high added value graphite-like materials, with a crystalline structure 
similar to that of oil-derived graphite which is currently commercialized to be used as anode in rechargeable lithium-ion batteries, were prepared from the corresponding BCNFs by heat treatment. On the basis of these results, the revaluation of biogas by CDB appears as an interesting alternative to direct biogas combustion.

\section{Acknowledgments}

The authors acknowledge the Spanish Economy and Competitiveness Ministry (MINECO) and the ERDF funds for the financial support of the Coordinated Project ENE2011-28318. The authors acknowledge EDP and BFC companies for the economical aid to carry out this work. S. de Llobet and N. Cuesta, respectively, thank the Diputación General de Aragón and the MINECO (BES-2012-052711) for Ph.D. grants to develop the work. A. Ramos thanks the Spanish Research Council for Scientific Research (CSIC) for a JAE-Doc contract, co-funded by the European Social Fund (ESF). 


\section{References}

[1] Walsh JL, Ross CC, Smith MS, Harper SR. Utilization of biogas. Biomass 1989;20:277-90.

[2] Xu J, Zhou W, Li Z, Wang J, Ma J. Biogas reforming for hydrogen production over nickel and cobalt bimetallic catalysts. Int J Hydrogen Energy 2009;34:6646-54.

[3] Lau CS, Tsolakis A, Wyszynski ML. Biogas upgrade to syn-gas (H2-CO) via dry and oxidative reforming. Int J Hydrogen Energy 2011;36:397-404.

[4] Corthals S, Van Noyen J, Geboers J, Vosch T, Liang D, Ke X, et al. The beneficial effect of $\mathrm{CO} 2$ in the low temperature synthesis of high quality carbon nanofibers and thin multiwalled carbon nanotubes from CH4 over Ni catalysts. Carbon 2012;50:37284.

[5] Ryckebosch E, Drouillon M, Vervaeren H. Techniques for transformation of biogas to biomethane. Biomass Bioenerg 2011;35:1633-45.

[6] Pinilla JL, de Llobet S, Suelves I, Utrilla R, Lázaro MJ, Moliner R. Catalytic decomposition of methane and methane/CO2 mixtures to produce synthesis gas and nanostructured carbonaceous material. Fuel 2011;90:2245-53.

[7] Wood gas as engine fuel. A report of the mechanical wood products branch of FAO Forestry: Food and Agriculture Organization of United Nations; 1986.

[8] Utilisation dans les moteurs de gaz pauvres obtenus à partir de déchets végétaux: Techniques de l'ingénieur. B3 Moteurs Thermiques. Imprimerie Strasbourgeoise, Strasbourg, France; 1972.

[9] Sridhar G, S. Dasappa, H.V. Sridhar, P.J. Paul and N.K.S. Rajan. Gaseous emissions using producer gas fuel in reciprocating engines. Proceedings of SAE Centenary Conference (SP-1978), Detroit, 10-14 April 2005 2005;2005-01-1732.

[10] Uma R, Kandpal TC, Kishore VVN. Emission characteristics of an electricity generation system in diesel alone and dual fuel modes. Biomass Bioenerg 2004;27:195203.

[11] Bhattacharya SC, Shwe Hla S, Pham HL. A study on a multi-stage hybrid gasifierengine system. Biomass Bioenerg 2001;21:445-60.

[12] Sridhar G, Paul PJ, Mukunda HS. Biomass derived producer gas as a reciprocating engine fuel - An experimental analysis. Biomass Bioenerg 2001;21:61-72. 
[13] Sridhar G, Sridhar HV, Dasappa S, Paul PJ, Rajan NKS, Mukunda HS.

Development of producer gas engines. Proc Inst Mech Eng D J Automot Eng 2005;219:423-38.

[14] Muñoz M, Moreno F, Morea-Roy J, Ruiz J, Arauzo J. Low heating value gas on spark ignition engines. Biomass Bioenergm2000;18:431-9.

[15] Shah A, Srinivasan R, D. Filip To S, Columbus EP. Performance and emissions of a spark-ignited engine driven generator on biomass based syngas. Bioresour Technol 2010;101:4656-61.

[16] Mustafi NN, Miraglia YC, Raine RR, Bansal PK, Elder ST. Spark-ignition engine performance with 'Powergas' fuel (mixture of $\mathrm{CO} / \mathrm{H} 2$ ): A comparison with gasoline and natural gas. Fuel 2006;85:1605-12.

[17] Shudo T, Nagano T, Kobayashi M. Combustion characteristics of waste-pyrolysis gases in an internal combustion engine. Int J Automot Techn 2003;4:1-8.

[18] Ando Y, Yoshikawa K, Beck M, Endo H. Research and development of a lowBTU gas-driven engine for waste gasification and power generation. Energy 2005;30:2206-18.

[19] Sebastián D, Ruíz AG, Suelves I, Moliner R, Lázaro MJ, Baglio V, et al. Enhanced oxygen reduction activity and durability of Pt catalysts supported on carbon nanofibers. Appl Catal B Environ 2012;115-116:269-75.

[20] Utrilla R, Pinilla JL, Suelves I, Lázaro MJ, Moliner R. Catalytic decomposition of methane for the simultaneous co-production of $\mathrm{CO} 2$-free hydrogen and carbon nanofibre based polymers. Fuel 2011;90:430-2.

[21] Cameán I, García AB, Suelves I, Pinilla JL, Lázaro MJ, Moliner R, et al. Influence of the inherent metal species on the graphitization of methane-based carbon nanofibers. Carbon 2012;50:5387-94.

[22] Garcia AB, Cameán I, Suelves I, Pinilla JL, Lázaro MJ, Palacios JM, et al. The graphitization of carbon nanofibers produced by the catalytic decomposition of natural gas. Carbon 2009;47:2563-70.

[23] Cameán I, García AB, Suelves I, Pinilla JL, Lázaro MJ, Moliner R. Graphitized carbon nanofibers for use as anodes in lithium-ion batteries: Importance of textural and structural properties. J Power Sources 2012;198:303-7.

[24] Arnold M. Reduction and monitoring of biogas trace compounds. Espoo: JULKAISIJA-UTGIVARE-PUBLISHER; 2009. 
[25] Dewil R, Appels L, Baeyens J. Energy use of biogas hampered by the presence of siloxanes. Energ Convers Manage 2006;47:1711-22.

[26] Pinilla JL, Utrilla R, Lázaro MJ, Suelves I, Moliner R, Palacios JM. A novel rotary reactor configuration for simultaneous production of hydrogen and carbon nanofibers. Int J Hydrogen Energ 2009;34:8016-22.

[27] Suelves I, Lázaro MJ, Moliner R, Echegoyen Y, Palacios JM. Characterization of $\mathrm{NiAl}$ and $\mathrm{NiCuAl}$ catalysts prepared by different methods for hydrogen production by thermo catalytic decomposition of methane. Catal Today 2006;116:271-80.

[28] de Llobet S, Pinilla JL, Lázaro MJ, Moliner R, Suelves I. Catalytic decomposition of biogas to produce H2-rich fuel gas and carbon nanofibers. Parametric study and characterization. Int J Hydrogen Energ 2012;37:7067-76.

[29] Pinilla JL, Suelves I, Lázaro MJ, Moliner R, Palacios JM. Influence of nickel crystal domain size on the behaviour of $\mathrm{Ni}$ and $\mathrm{NiCu}$ catalysts for the methane decomposition reaction. Appl Catal A Gen 2009;363:199-207.

[30] Arroyo J, Moreno F, Muñoz M, Monné C. Efficiency and emissions of a spark ignition engine fueled with synthetic gases obtained from catalytic decomposition of biogas. Int J Hydrogen Energ 2013;38:3784-92.

[31] Moreno F, Munoz M, Morea-Roy J. Sunflower methyl ester as a fuel for automobile diesel engines. Trans Am Soc Agric Eng 1999;42:1181-5.

[32] Heywood JB. Internal Combustion Engine Fundamentals: McGraw-Hill Science Engineering; 1988.

[33] Moreno F, Muñoz M, Arroyo J, Magén O, Monné C, Suelves I. Efficiency and emissions in a vehicle spark ignition engine fueled with hydrogen and methane blends. Int J Hydrogen Energ 2012;37:11495-503.

[34] Biscoe J, Warren BE. An X-Ray Study of Carbon Black. J Appl Phys 1942;13:36471.

[35] Cuesta A, Dhamelincourt P, Laureyns J, Martinez-Alonso A, M. D. Tascon J. Comparative performance of X-ray diffraction and Raman microprobe techniques for the study of carbon materials. J Mater Chem 1998;8:2875-9.

[36] Franklin R. The structure of graphitic carbons. Acta Crystallographica 1951;4:25361.

[37] Emmerich FG. Evolution with heat treatment of crystallinity in carbons. Carbon 1995;33:1709-15. 
[38] Marsh H, Warburton AP. Catalysis of graphitisation. J Appl Chem 1970;20:13342.

[39] Oberlin A, Rouchy JP. Transformation des carbones non graphitables par traitement thermique en presence de fer. Carbon 1971;9:39-46.

[40] Ramos A, Cameán I, García AB. Graphitization thermal treatment of carbon nanofibers. Carbon 2013. 
Table 1. Elemental composition of the BCNFs (wt. \% and dry basis)

\begin{tabular}{lcccccc} 
BCNFs & $\mathrm{C}$ & $\mathrm{N}$ & $\mathrm{H}$ & $\mathrm{O}$ & $\mathrm{Ni}$ & $\mathrm{Al}$ \\
\hline BCNF1-6 & 87.46 & 0.17 & 0.18 & 1.09 & 5.11 & 1.47 \\
BCNF1-7 & 82.66 & 0.22 & 0.12 & 0.81 & 6.80 & 2.01 \\
\hline
\end{tabular}


Table 2. Original engine specifications

\begin{tabular}{ll} 
Engine & Lombardini LGW 523 MPI SI engine \\
\hline Number of cylinders & 2 in line \\
\hline Bore x Stroke & $72 \times 62 \mathrm{~mm}$ \\
\hline Compression ratio & $10.7: 1$ \\
\hline Valves per cylinder & 2 \\
\hline Fuel delivery system & Electronic indirect fuel injection \\
\hline
\end{tabular}


Table 3. SG composition (v:v, dry basis), $\mathrm{CH}_{4}$ and $\mathrm{CO}_{2}$ conversions (\%), molar expansion factor $\left(\varepsilon_{\mathrm{a}}\right)$ and $\mathrm{BCNFs}$ production obtained in the CDB process

\begin{tabular}{|c|c|c|c|c|c|c|c|c|c|c|}
\hline $\mathrm{SG}$ & $\mathrm{CH}_{4}: \mathrm{CO}_{2}$ & $\begin{array}{l}\mathrm{T} . \\
\left({ }^{\circ} \mathrm{C}\right)\end{array}$ & $\begin{array}{l}\mathrm{H}_{2} \\
(\%)\end{array}$ & $\begin{array}{l}\mathrm{CO} \\
(\%)\end{array}$ & $\begin{array}{l}\mathrm{CH}_{4} \\
(\%)\end{array}$ & $\begin{array}{l}\mathrm{CO}_{2} \\
(\%)\end{array}$ & $\begin{array}{l}\mathrm{X}_{\mathrm{CH} 4} \\
(\%)\end{array}$ & $\begin{array}{c}\mathrm{X}_{\mathrm{CO} 2} \\
(\%)\end{array}$ & $\begin{array}{c}\varepsilon_{\mathrm{a}} \\
(\%)\end{array}$ & $\begin{array}{c}\text { BCNFs } \\
\left(\mathrm{gC} \cdot \mathrm{g}_{\mathrm{cat}}^{-1} \cdot \mathrm{h}^{-1}\right)\end{array}$ \\
\hline SG1-6 & \multirow{2}{*}{$50: 50$} & 600 & 23 & 23 & 26 & 28 & 37 & 34 & 19 & 2.0 \\
\hline SG1-7 & & 700 & 40 & 39 & 11 & 10 & 71 & 66 & 54 & 1.4 \\
\hline SG2-6 & \multirow{2}{*}{$60: 40$} & 600 & 26 & 19 & 34 & 21 & 33 & 37 & 19 & 2.5 \\
\hline SG2-7 & & 700 & 45 & 34 & 14 & 7 & 65 & 71 & 53 & 2.5 \\
\hline SG3-6 & \multirow{2}{*}{$70: 30$} & 600 & 34 & 17 & 36 & 13 & 37 & 46 & 23 & 3.4 \\
\hline SG3-7 & & 700 & 53 & 29 & 14 & 4 & 67 & 79 & 61 & 3.6 \\
\hline
\end{tabular}


Table 4. Maximum and minimum brake thermal efficiencies (BTE) of the engine at full load and different equivalence ratios

\begin{tabular}{l|c|c|c|c|c|c} 
& \multicolumn{2}{|c|}{ BTE at $\Phi=1(\%)$} & \multicolumn{2}{|c|}{ BTE at $\Phi=0.85(\%)$} & \multicolumn{2}{c}{ BTE at $\Phi=0.7(\%)$} \\
Fuel & Min. & Max. & Min. & Max. & Min. & Max \\
\hline BG2 & 22.76 & 27.24 & 22.31 & 25.16 & - & - \\
\hline SG1-6* & 26.51 & 28.41 & 27.57 & 31.65 & 22.47 & 26.17 \\
\hline SG1-7* & 23.73 & 28.29 & 28.87 & 30.48 & 23.96 & 28.48 \\
\hline
\end{tabular}


Table 5. Interplanar distance $d_{002}$, and crystallites sizes $L_{c}$ and $L_{a}$ of (a) BCNF1-6 and BCNF1-7 bio-carbon nanofibers, (b) graphitic materials prepared from BCNF1-6 and BCNF1-7 and (c) G1 and G2 graphites of reference

\begin{tabular}{lccc} 
Material & $\mathrm{d}_{002}(\mathrm{~nm})$ & $\mathrm{L}_{\mathrm{c}}(\mathrm{nm})$ & $\mathrm{L}_{\mathrm{a}}(\mathrm{nm})$ \\
\hline BCNF1-6 & 0.3417 & 6.3 & 22.9 \\
BCNF1-6/2600 & 0.3407 & 8.9 & 27.5 \\
BCNF1-6/2800 & 0.3405 & 9.3 & 34.4 \\
BCNF1-6-1/2800 & 0.3398 & 9.7 & 37.2 \\
BCNF1-6-5/2800 & 0.3378 & 15.9 & 53.5 \\
BCNF1-6-7/2800 & 0.3367 & 24.0 & 58.5 \\
\hline BCNF1-7 & 0.3422 & 6.1 & 23.1 \\
BCNF1-7/2600 & 0.3425 & 6.6 & 23.4 \\
BCNF1-7/2800 & 0.3400 & 9.3 & 40.4 \\
BCNF1-7-1/2800 & 0.3390 & 11.5 & 49.8 \\
BCNF1-7-5/2800 & 0.3362 & 36.1 & 96.6 \\
BCNF1-7-7/2800 & 0.3361 & 42.4 & 98.5 \\
\hline G1 & 0.3360 & 47.0 & 99.5 \\
\hline G2 & 0.3361 & 50.4 & 102.3 \\
\hline
\end{tabular}




\section{CAPTIONS FOR FIGURES}

Figure 1. Schematic diagram of the engine test bench

Figure 2. Representative SEM and TEM images of BCNF1-6(a, c) and BCNF1-7 (b, d)

Figure 3. Brake specific exhaust emissions of the engine at the points with maximum BTE: (a) $\mathrm{BSCO}_{2}$, (b) BSCO, (c) BSHC and (d) BSNOx 
Figure 1




Figure 2

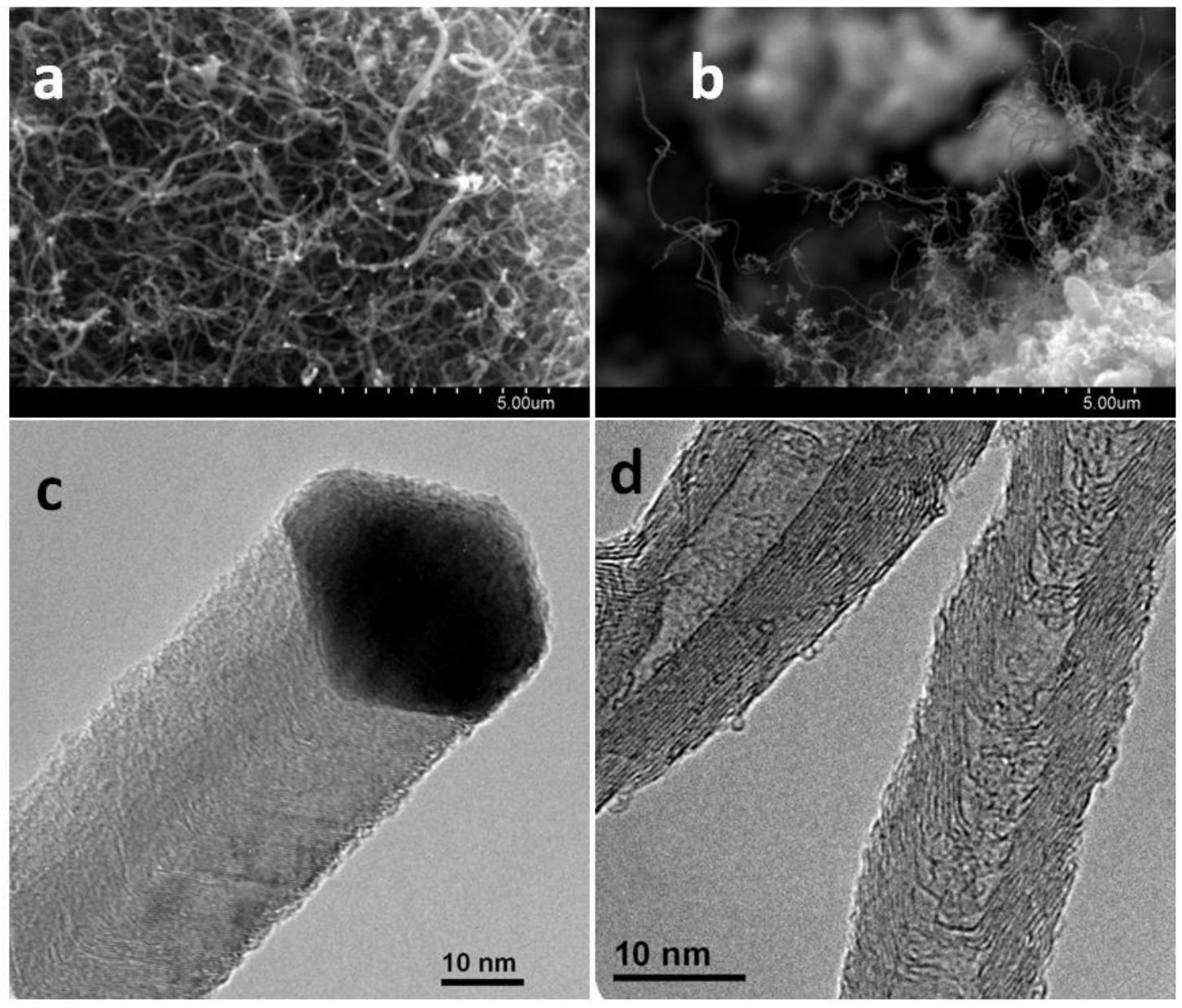


Figure 3
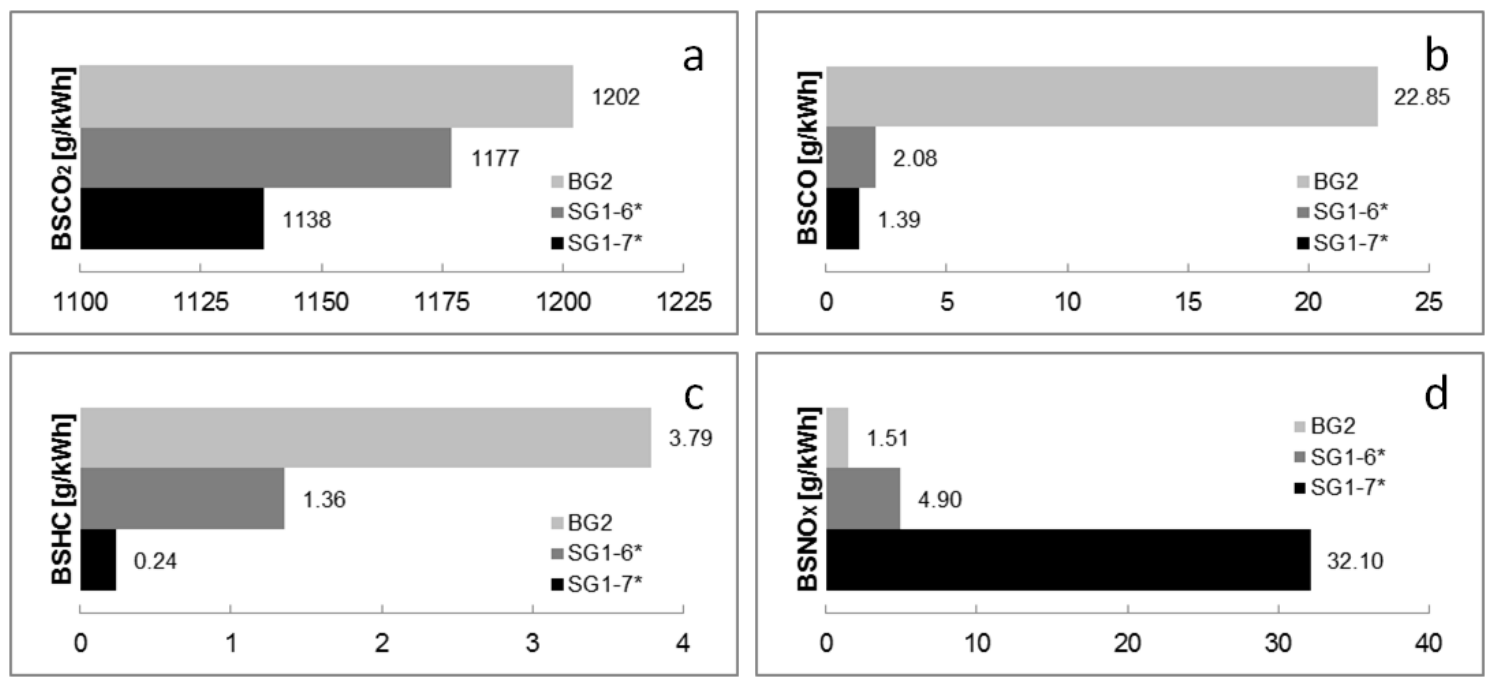